\title{
Basics of building a risk-management system at mining enterprises
}

\author{
Alena Chupryakova ${ }^{1 *}$, Petr Kosinsky ${ }^{2}$, and Rimma Takhtayeva ${ }^{3}$ \\ ${ }^{1}$ T.F. Gorbachev Kuzbass State Technical University, Belovo Branch, 652644, Ilyicha st. \\ 32, Belovo, Russia \\ ${ }^{2}$ T.F. Gorbachev Kuzbass State Technical University, 650000, 28 Vesennyaya st. \\ Kemerovo, Russia \\ ${ }^{3}$ Kazakh Humanitarian and Legal Innovation University, Semey City, Republic of \\ Kazakhstan
}

\begin{abstract}
This paper reflects the problematic situation in the field of riskmanagement at mining enterprises. It is connected with the fact that not all hired top managers understand the role and importance of the risk management system in the overall management system of a mining enterprise. However, an increase in the number and weight of the consequences of the onset of risk events has recently changed the vision of senior management, business owners and other stakeholders in favor of recognizing the need to create in the structure of mining enterprises, if not separate, specialized structural units, in the form of a risk management service, then at least introduction of a staff unit of a specialist - a riskmanager, who clearly understands what the organization is doing to form and increase the value of a business and how he can influence this, demonstrating his professional knowledge, skills, and even some insight in anticipating future risks of a mining enterprise ... But the economic situation in the region, the country and the world does not allow, due to financial constraints, to fully implement the technologies developed in theory and fixed in practice for the application of methods and approaches to risk management in the mining industry, including the purchase of expensive software products that allow the formation of an effective risk-management system. Therefore, mining risk management professionals need to take full advantage of the potential and benefits of the GRC system, which has existed since 2004, which aims to use a common language and corporate risk management methodology to achieve the company's strategic goals. The results of the studies presented in this paper state that the main risks that the owners of mining enterprises are concerned about are financial risks and operational risks, legal risks, commercial risks and the risk of fraud, as well as natural, environmental and man-made risks, but a significant part of mining enterprises in the region does not have a well-developed risk management system, does not carry out systematic work to identify risks, assess risks and their possible consequences, and therefore: either operate at extreme risk, taking catastrophic risk, or work at the margin of profitability, refusing to accept risks, even there, where you really need it. However, one should proceed from their understanding that technologies in the field of
\end{abstract}

\footnotetext{
* ${ }^{*}$ Corresponding author: chupa.69@mail.ru
} 
corporate governance of mining enterprises, including risk management, can not only form lines of defence against risks, but also increase the value of a mining enterprise through an effective risk-management system.

\section{Introduction}

The scientific community has proven that there are very few conventionally risk-free objects. All human activity takes place in deterministic conditions. Any commercial structure that exists for the sake of deriving benefits, most often in the form of profit, by satisfying social needs. Mining enterprises in this interpretation are no exception. Consequently, business owners, top managers and other stakeholders should understand that in modern conditions, risk-management is one of the key areas in the management of a mining enterprise. Unfortunately, the modern reality is such that not everyone understands this, even when they often face risky situations in the professional sphere. Therefore, updating knowledge in the field of risk management, promoting business at a profitability level above the industry average on the basis of building an effective risk-management system are the tasks of this work.

Today, only large coal companies can afford to have a separate structural unit - the riskmanagement service, whose functions include specialization in risk management issues. The usefulness of such a unit in the structure of a coal enterprise is determined by two criteria: the generated and incremental value of the company (business) itself and the costs of generating this value. And the higher the cost and the lower the costs of its formation, the higher the added value of this business. And as soon as the owners and top management of the coal company have a clear vision of this, they understand that the resources spent on the needs of this structural unit (salaries of their specialists, costs for co-sourcing and outsourcing, software, etc.) not only pay off, but also bring tangible results, gains. And on the part of risk managers, there should be a clear understanding of what the organization is doing to form and increase the value of the business. This is the basis for the manifestation of business acumen and the application of professional knowledge, skills and abilities to identify opportunities for improving corporate governance processes in general, and risk management in particular, that is, the implementation of the principles of management of agreed improvements.

In most cases, the awareness of the need for risk-management at the enterprise level does not correspond to its financial capabilities, and therefore, instead of a specialized structural unit, one has to be content with only the introduction of a staff unit of a risk manager in the financial department to resolve issues of management of financial, credit, currency, investment risks, while other types of risks are managed by traditional divisions of a coal enterprise, such as the security service (overseeing information, fire and other types of security at the enterprise), personnel management (overseeing personnel risks), technical and technological services (overseeing operational, technological risks), etc. .d..

\section{Materials and methods}

It should be noted that international practice knows examples of successful cooperation between various structural units within the framework of overall risk management. Since 2004, there has even been a GRC system (usually a combination of the terms "control" and 
"compliance" is used to decipher the abbreviation), the purpose of which is to provide a common language and methodology for corporate risk management to achieve the strategic goals of the company. This is a kind of common knowledge base and development of cooperation, communications between structural units in risk management issues. Of course, such a system has a number of advantages, since each structural unit brings together specialists with important specialized knowledge, and if they communicate "in the same language", the interaction between them within the framework of specific risks management will be effective by providing appropriate control mechanisms, eliminating them risks in accordance with its purpose and effective use of available resources. But in the case of the Russian practice of separate management of various types of risks by separate structural divisions, this is not an introduction to the GRC system, but a tribute to the crisis in the national economy.

In the Western theory of riskology, a number of methodological principles for building a risk management system from an organization have been developed and the expediency of their application has been proven in practice, methods for identifying, identifying, assessing and managing risks of various etiologies have been tested.

To disclose the essence of the category "risk", it is recommended to study such concepts as "damage", "random nature of events", "probability", "object of risk", as well as the concept of "risk capital" (otherwise "risk appetite"), which shows the acceptable level of risk for a particular organization from the point of view of a tolerant attitude towards it on the part of owners and top managers. The risk management service should be guided in its actions by reducing the risk to a level within the risk capital of the coal company.

The value of the risk-management service of a coal company, first of all, lies in the fact that it provides guarantees that the main risks accompanying the achievement of the company's goals are identified, described, identified, and effectively managed.

\section{Results and discussion}

In the course of the conducted studies of the state of the risk-management system of coal companies in the region, it was concluded that the vision of business owners regarding the composition of risks inherent in this entrepreneurial activity coincides with the vision of top managers of coal enterprises. The main ones are financial risks and operational risks this is the first group that receives the most attention, the second group includes legal risks, commercial risks and the risk of fraud, the third group includes natural, environmental and man-made risks.

Among the main reasons for the strengthening of the role of risk-management, we noted:

- firstly, the desire of the owners to be calm about their own business;

- secondly, increasing the overall transparency of the business;

-third, increasing the responsibility of hired top managers to the owners of the companies;

- fourthly, changes in legislation;

- fifth, the growth of general volatility in business communities.

According to the results of the study, it was also revealed that only half (48\%) of the interviewed top managers stated the presence of a risk management specialist in the organization's structure and an approved risk-management policy; a third of the respondents know about the existence of risk management standards and documented schemes (ERM COSO), but practically do not use them in their activities; about half of the respondents make risk maps at the corporate level. In addition, it was noted that some executives are afraid of disclosing real information, therefore they answered evasively questions, and also 
viewed risk-management as a way to justify future failures in the form of reduced profits, sales volumes and increased costs.

It is also depressing that a significant part of mining enterprises does not have a welldeveloped risk management system, does not carry out systematic work to identify risks, assess risks and their possible consequences, and therefore: either operate at extreme risk, taking catastrophic risk, or operate at the margin of profitability, refusing to take risks, even where it is really needed.

The conclusions based on the results of our research also indicate that in modern Russian practice information technologies are recognized as an integral part of business processes, but they are not integrated into the risk-management system. The main reason is the high cost of software products and the lack of confidence among the owners of coal enterprises in the readiness of specialists of a particular mining enterprise to adequately use all the possibilities of the purchased program in the field of risk management, since a highquality risk assessment requires critical thinking, professional judgment, as well as analysis of the effectiveness of control practice beyond the risks. Thus, the fact of high personnel risk at mining enterprises is stated.

\section{Conclusion}

A common vision and understanding of the role of risk-management at mining enterprises determines the choice of risk assessment methods used to achieve high results from assessing the maximum number of risks inherent in the activities of mining enterprises. In this regard, two general objectives of risk assessment in mining operations can be distinguished:

- maintaining an up-to-date risk profile and, as a consequence, the selection of controls used to manage these risks;

- finding an opportunity to allocate funds for the formation of an effective risk management system, including the purchase of specialized software for this activity to improve the efficiency of the processes of identifying, describing, identifying, assessing and ensuring protection against risks of various etiologies.

Specialists in charge of coordinating the communication interaction of structural units for risk management at a mining enterprise should focus their efforts on the risks inherent in the implementation of strategic goals. These specialists should participate in the work of temporary structures and working groups in order to promptly propose methods of localization, evasion, and delegation of emerging risks appropriate to a specific risk situation. Their functions should include monitoring, scanning and interpreting the market environment for early warning of external risks.

Technologies in the field of corporate governance of mining enterprises, including riskmanagement, can not only form lines of defense against risks, but also increase the value of a mining enterprise through an effective risk management system.

\section{References}

1. N. Zaruba, N.Egorova, P. Kosinskij. E3S Web Of Conferences , 04003 (2017)

2. Hans Beumer "Audit Risk Management" Volume 2 (Zug, Switzerland: Hans Beumer Pablication, 35, 55(2017)

3. Paul Sobel, "The Auditor's Risk Management Guide: Integrating Auditing and Organizational Risk Management" (Chicago, IL: CLO, Inc, 2015) 
4. Practical guide IIA "Assessment of the adequacy of risk management according to ISO 31000" (Lake Mary, Florida: International Institute of Internal Auditors, (2012)

5. Kosinskiy P. D. Ecological component of the quality of life of the population: regional aspect//International Journal of Applied and Fundamental Research. No. 6(3), 484 (2015)

6. Vladimir Merkuriev Piotr Kosinskiy and Aleksey Medvedev. Approaches to Evaluation of Environmental and Economic Damage to the Kuzbass Agglomeration Caused by Coal Mining Industry Development Published online (2019)

7. Practical Guide IIA "Coordinating Activities and Leveraging Outputs: Mapping Safeguards" (Lake Mary, Florida: International Institute of Internal Auditors, 2018)

8. T. V.Kiseleva, V. G. Mikhailov, Management of current environmental costs contributing to reduce eco-economic risks B сборнике: IOP Conference Series: Earth and Environmental Science, 012050 (2018)

9. Mark L. Frigo "Balanced Scorecard. Internal Audit and Risk Management Applications" (Lake Mary, FL: Internal Audit Foundation, 2014)

10. Baklanova, O., Petrova, M., Koval, V. Ikonomicheskilzsledvania (Economic Studies), 29(1), 68 (2020).

11. Jarmusevica, V.; Ilisko, D.; Badjanova, J.; Jukss, V.; Petrova, M. Conference 1st3rd, Palma, Mallorca, Spain, 10449 (2019)

12. T.Jurzina, N.Egorova, N.Zaruba, P.Kosinskij. Tools of realization of social responsibility of industrial business for sustainable socio-economic development of mining region's rural territory, E3S Web of Conferences (2017)

13. T. A.Yurzina, N. N.Yegorova. Development of rural areas of the industrial region on the basis of social responsibility of business//Economics and entrepreneurship, 8-1(85), 380 (2017) 